\title{
XENOTRANSPLANTATION OF PIG CHONDROCYTES: THERAPEUTIC POTENTIAL AND BARRIERS FOR CARTILAGE REPAIR.
}

\author{
R. Sommaggio, M. Uribe-Herranz, M. Marquina and C. Costa* \\ Infectious Diseases and Transplantation Division, Bellvitge Biomedical Research Institute (IDIBELL), \\ L’Hospitalet de Llobregat, Barcelona, Spain
}

\begin{abstract}
Transplantation may be the best option for the repair of many cartilage lesions including early osteoarthritis. Currently, autologous and allogeneic chondrocytes are grafted into cartilage defects to treat selected patients with moderate clinical success. However, their limited use justifies exploring novel therapies for cartilage repair. Xenotransplantation could become a solution by offering high cell availability, quality and genetic engineering capabilities. The rejection process of xenogeneic cartilage is thus being elucidated in order to develop counteractive strategies. Initial studies determined that pig cartilage xenografts are rejected by a slow process comprising humoral and cellular responses in which the galactose $\alpha 1,3$-galactose antigen participates. Since then, our group has identified key mechanisms of the human response to pig chondrocytes (PCs). In particular, human antibody and complement contribute to $\mathrm{PC}$ rejection by inducing a pro-inflammatory milieu. Furthermore, PCs express and up-regulate molecules which are functionally relevant for a variety of cellular immune responses (SLA-I, the potent co-stimulatory molecule CD86, and adhesion molecules VCAM-1 and ICAM-1). These participate by triggering a $\mathrm{T}$ cell response, as well as supporting a prominent role of the innate immune responses led by natural killer (NK) cells and monocytes/macrophages. Human NK cells lyse PCs by using selected NK activating receptors, whereas human monocytes are activated by PCs to secrete cytokines and chemokines. All this knowledge sets the bases for the development of genetic engineering approaches designed to avert rejection of xenogeneic chondrocytes and leads the way to developing new clinical applications for cartilage repair.
\end{abstract}

Keywords: Xenotransplantation, cartilage, antibody, complement, T cells, monocytes, NK cells, cytokine release.

*Address for correspondence:

Cristina Costa

IDIBELL, Hospital Duran i Reynals

Gran Via de L'Hospitalet 199

08908 L'Hospitalet de Llobregat

Barcelona, Spain

Telephone Number: +34-93-2607355

FAX Number: +34-93-2607426

E-mail: ccosta@idibell.cat

\section{Introduction}

There is a lack of good curative therapies for many cartilage diseases such as traumatic injury, rheumatoid arthritis and osteoarthritis. In spite of some advances in chondrocyte implantation and cartilage tissue engineering and transplantation, none of these advanced therapies are widely used in the clinic. The most frequently applied solution is still control of disease progression and pain, followed by prosthesis implantation when needed. Due to the very low regenerative capacity of cartilage, transplantation is considered the best option for the repair of many cartilage defects. Although results are still not optimal, autologous and occasionally allogeneic chondrocytes are grafted into articular cartilage defects in selected patients with fair outcomes (Saris et al., 2014; Gillogly et al., 2015; Basad et al., 2015). Full meniscus allografts (Stone et al., 2015) and laryngeal and tracheal autografts (Fabre et al., 2013) are also being tested in a few patients with some encouraging results. Finally, compatible implants for facial plastic surgery and intervertebral disc repair are also needed (Yanaga et al., 2009; Fulco et al., 2014; Oehme et al., 2015). The limited availability of human tissue/cells for these various applications has led searches for another suitable cell source. In this regard, the use of mesenchymal stem cells (MSCs) has received much attention, but further studies are needed to ensure patient safety and functional recovery. This particular topic has been reviewed in depth elsewhere (Madeira et al., 2015; Vonk et al., 2015; Pers et al., 2015). Although less explored, xenotransplantation is another option which shows great potential for cartilage repair. Xenogeneic donor cells and tissues could be adapted by genetic engineering to the intended clinical applications and be produced under controlled conditions in sufficient quantities to cover all medical needs. Thus, it could be the basis for the development of one or more off-the-shelf products for cartilage repair that could be easily handled by orthopedic surgeons in many centers, preferably without the need of immunosuppression. The path towards this goal entails elucidating the cellular and molecular mechanisms that trigger and effect the rejection of xenogeneic chondrocytes and cartilage. This knowledge will allow the development of genetic engineering strategies that prevent rejection. In this review, we briefly describe the potential applications of xenotransplantation in the field of cartilage repair and gather together information available regarding the rejection process of xenogeneic cartilage/chondrocytes. 


\section{Current Clinical Needs}

Cartilage defects or disease can affect all kinds of cartilage. The main types of cartilage are: 1) Hyaline cartilage, the most abundant, which is located at the end of long bones, anterior ends of ribs, nose, parts of the larynx, trachea, bronchi, bronchial tubes and the embryonic/fetal skeleton. It provides flexibility and support, and in the joints reduces friction and absorbs shock. 2) Elastic cartilage, located on the top of the epiglottis, in the auricle of the ears and in the Eustachian tubes. It provides strength and elasticity, and maintains shape. 3) Fibrous cartilage, the strongest of the three, composes the pubic symphysis, intervertebral discs and menisci.

The origin of cartilage defects can be traumatic injury (acute or chronic), surgical resection associated with malignancies, and in some cases congenital (microtia/ anotia for defective or missing ear/s). Regarding cartilage diseases, the most common is osteoarthritis (OA) followed by rheumatoid arthritis (RA). OA is an agingrelated disease, especially prevalent in obese patients, causing disability in many people worldwide (GlynJones et al., 2015; Musumeci et al., 2015). It affects the articular cartilage, but also all structures of weightbearing joints. The inflammatory response associated with this disease induces cartilage deterioration through abnormal remodeling of extracellular matrix and loss of joint structure (Malemud, 2015; Musumeci et al., 2015). RA is a chronic and systemic inflammatory disorder with autoimmune and innate-immunity components that principally attacks the joints (Arend and Firestein, 2012; Catrina et al., 2016). RA produces synovitis that often progresses to destruction of articular cartilage and ankylosis of the joint. Clinical symptoms which differ from $\mathrm{OA}$ are the fast and potentially early onset, the symmetry of affected joints (in both sides) and the presence of systemic symptoms such as fatigue. Both of these diseases are mostly managed with anti-inflammatory agents, including expensive biological therapies such as anti-TNF for RA. Despite their therapeutic efficacy, there is still a pressing need for better treatments.
Cartilage is unable to develop a satisfactory healing response after injury or disease. Even small damage produced by traumatic injury is difficult to repair. Pure chondral defects, such as those that do not penetrate the underlying subchondral bone in joints, are unable to repair by themselves (the lack of vessels does not allow the fast access of macrophages and native MSCs) and may pass undetected (cause no pain without innervations). Full-thickness chondral and osteochondral defects produce pain and inflammation, but do not have a better outcome. Notably, hyaline cartilage lesions, unless treated appropriately, generate a fibrous scar that has different structure, composition and inferior mechanical proprieties than the original cartilage. Furthermore, these lesions often progress towards $\mathrm{OA}$ affecting the entire joint. Interestingly, fibrocartilage, such as in menisci, also does not repair spontaneously. Therefore, the great medical needs and the prospect of better therapies have promoted intense research in cartilage transplantation and tissue engineering, especially for the cure of traumatic joint injuries in athletes. As mentioned, other indications under study are nasal, auricular and laryngeal/tracheal reconstructions, as well as intervertebral disc repair. A scheme of current clinical needs for cartilage repair is shown in Fig. 1.

\section{Currently Available Therapies for Cartilage Repair}

Several therapeutic options are available for the repair of damaged articular cartilage. Microfracture, used for promoting subchondral bleeding and bone marrow stimulation, is the simplest procedure for treating articular chondral defects. It is recommended in the case of small lesions $\left(<2 \mathrm{~cm}^{2}\right)$, as it basically results in fibrocartilage (Oussedik et al., 2015). For this reason, some teams are working on a related technique called autologous matrixinduced chondrogenesis that combines microfracture with the implantation of a cover scaffold that stabilizes the clot (Lee et al., 2014). The impact of this particular strategy remains to be clarified after longer experience.

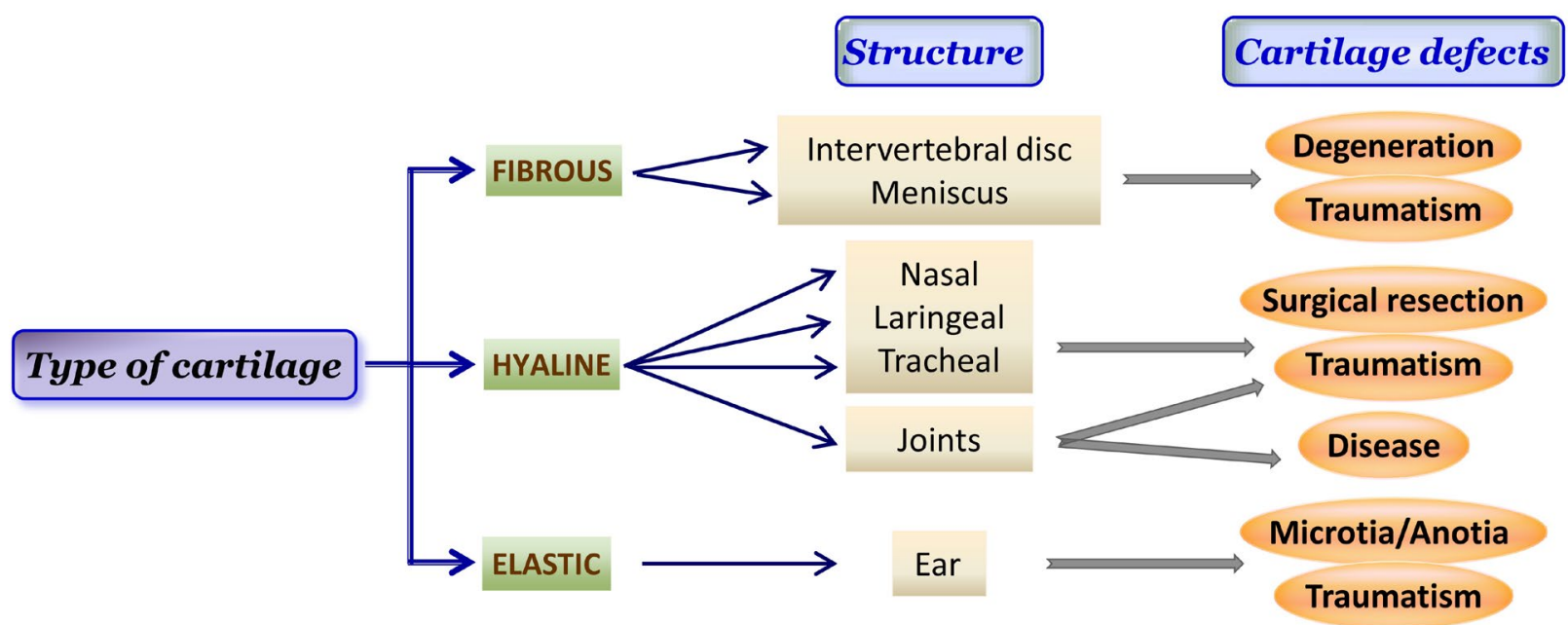

Fig. 1. Scheme of the current clinical needs for cartilage repair categorized by type of cartilage, affected structure and general cause of pathology. 
For larger defects, a more frequently-used approach is osteochondral graft transplantation that is commonly based on implantation of an autograft obtained from a healthy and low-stress area in the same joint. Depending on the severity, shape and overall size of the damage, multiple plugs or use of allogeneic tissue may be required to adequately repair the joint. Mosaicplasty, in particular, involves the implantation of multiple autologous osteochondral plugs that replace damaged cartilage on the joint surface. As described by Berta et al. (2015), this technique offers effective management of small and medium-sized focal defects although it does not result in good hyaline cartilage.

Allotransplantation is particularly considered for settings that require whole structures such as menisci, large number of cells and/or when other techniques of cartilage repair have failed (Stone et al., 2015; Gracitelli et al., 2015). Despite the clinical benefit attained with meniscus allotransplantation and osteochondral allograft transplantation (Stone et al., 2015; Gracitelli et al., 2015), some concerns have been raised about the potential detrimental effects of the elicited immune response. Evidence is accumulating of the immune-privileged properties of cartilage, but isolated chondrocytes and especially the bony portion of the osteochondral grafts are more immunogenic (Smith et al., 2015). Early work pointed out that allogeneic chondrocytes may elicit an immune response when injected heterotopically in rats (Romaniuk et al., 1995). In this model, new cartilage-like tissue was formed, but over time it was destroyed displaying an infiltrate of mononuclear immune cells (comprised mainly by macrophages shortly after transplantation and a large population of NK and T cells at later stages). On the other hand, harvest and storage of the donor tissue in a timely manner can be difficult. Consequently, limitations associated with cryopreservation or prolonged refrigerated storage have been described. such as reduced viability and metabolism of chondrocytes (Berta et al. 2015). In summary, there are also disadvantages for therapies based on chondrocyte/cartilage allotransplantation.

Cartilage diseases very often lead to a point of pain and loss of function that is only solved by utilizing a medical device. Orthopedic prostheses made of stainless steel and titanium alloys in addition to other materials are frequently used for joint replacements (Dearnley, 1999). Spinal fixation devices are also being considered as prosthetic solutions when intervertebral discs are failing (Slone et al., 1993). As advantages, these orthopedic implants are immediately available and are designed to be adapted and fixed within minutes leading to fast reconstruction. However, the process of implantation of prosthetic devices is costly, highly traumatic and can lead to multiple complications, such as infection, inflammation and pain. Furthermore, such prosthetic implants have a limited lifespan (Glyn-Jones et al., 2015) and pose the risk of inducing biomaterial hypersensitivity (Mitchelson et al., 2015).

\section{Transplantation of human chondrocytes}

Strategies based on transplantation of chondrocytes are currently the most successful therapies for articular cartilage repair. Nevertheless, its use in clinical practice is restricted for economical and technical reasons to a few centers treating a limited number of patients. The most accepted approaches utilize autologous chondrocytes, although implantation of allogeneic chondrocytes is also feasible. The autogeneic transplantation comprises the autologous chondrocyte implantation (ACI) and the next-generation procedure called matrix-induced or matrix-assisted ACI (MACI) because it involves the use of a filling material (Madeira et al., 2015). ACI and MACI both require the harvest of thin slides of cartilage from minor weight-bearing areas of the joint cartilage, which are subjected to enzymatic digestion for subsequent ex vivo expansion of chondrocytes for several weeks and final implantation into the defect. Significant and durable benefits have been demonstrated for patients subjected to these procedures in terms of diminished pain and improved function. Clinical values of repair, such as the degree of integration of donor cartilage, macroscopic appearance and mechanical assessment, are consistently good. Regarding ACI in particular, up-to-20-years repair has already been documented in some cases and the use of a porcinederived membrane to cover the defect has diminished the inconveniencies of the first-generation ACI (which involved a periostal flap) (Gillogly et al., 2015). Although the experience with MACI is shorter in time, it has been demonstrated to be more effective than microfracture for knee defects larger than $3 \mathrm{~cm}^{2}$ (Saris et al., 2014). For now, the available experience shows that MACI is technically easier than ACI, but it is unclear whether it is superior in terms of quality of repair and clinical benefit. The existence of different matrices and associated products, as well as medical centers for its application adds complexity and difficulty for evaluating efficacy (Madeira et al., 2015). Nonetheless, either ACI or MACI seem to be the first choice for treating this type of lesion, whereas other approaches could be applied for patients failing to respond well to these therapies (Basad et al., 2015).

Despite these promising clinical results, the use of these advanced therapies carries a number of limitations. One major issue is the high cost of the procedure. Another is the low tissue availability and the loss of phenotype of the chondrocytes during expansion (Madeira et al., 2015). As a result, the quality of the cartilage generated is compromised (Cucchiarini et al., 2014). Early magnetic resonance studies indicated the presence of fibrous tissue in the repair areas after ACI, which was later confirmed by quantitative analyses (Långsjö et al., 2010). In other studies, the chondrocyte implantation occurred at a slower rate than in osteochondral transplantation and the graft showed an inhomogeneous hyaline appearance (Horas et al., 2003). Other considerations for these techniques include the patient age, the rehabilitation regimens, postoperative joint alignment and surgical history (Berta et al., 2015). The lack of a consistent repair with hyaline cartilage after ACI or MACI has led to the proposal of combination therapy, such as microfracture with MACI (Cucchiarini et al., 2014). It is an interesting concept, but it does not imply a clear reduction in costs, unless the isolation and/or culture of chondrocytes is avoided. 


\section{State of the Art in Xenotransplantation}

Xenotransplantation has gained attention in the last decades as it could be used for the treatment of many diseases characterized by tissue loss or failure (Ekser et al., 2012). Based on the transplantation of cells, tissues and organs across different species, it has the potential to overcome the severe shortage of human cells, tissues and organs for clinical transplantation (Ekser et al., 2015). Its applicability has gained feasibility with the recent advancements made in the field of animal genetic engineering (Estrada et al., 2015; Yang et al., 2015; Cooper et al., 2016; Niemann and Petersen, 2016). Xenotransplantation offers an unlimited supply of cells that can be obtained under very high quality standards (Ekser et al., 2015). Accordingly, hormones and decellularized or devitalized tissues of animal origin are already being used in the clinic for therapeutic purposes (Vadori and Cozzi, 2015). New therapies could be developed in the future by using xenogeneic cells and tissues selected by their regenerative capacity and adapted to the intended clinical application by genetic engineering (Costa et al., 2003; Sommaggio et al., 2015).

The pig is now considered the best animal source for xenotransplantation because it is domesticated, reproduces in large scale and has a primate-like size of organs and physiology. Consequently, major efforts and advancements have been made to genetically modify pigs to the germ-line level using various technologies (Lai et al., 2002; Estrada et al., 2015; Yang et al., 2015). Thus, the pig has been chosen as the most appropriate animal source not only for solid organ xenotransplantation, but also for the development of xenogeneic cellular therapies (Ekser et al., 2012).

Immune rejection is the main hurdle to overcome for xenotransplantation to become a broad clinical reality. Three types of rejection could be assigned to solid organ xenotransplatation depending on the time of rejection: hyperacute rejection (HAR), acute xenograft rejection (AXR) comprising acute humoral xenograft rejection (AHXR) and acute cellular xenograft rejection, and in a few cases of long-term survival, there are pathological features consistent with chronic xenograft rejection (Cooper et al., 2015). HAR basically results from a humoral response. In general, humoral responses are those mediated by antibodies (produced by B cells) and their effector functions through complement activation, promotion of phagocytosis and antibody-dependent cell-mediated cytotoxicity (ADCC). In contrast, cellular responses are mediated by $\mathrm{T}$ cells that can develop direct effector functions (cytotoxicity) or enhance the activity of other cells such as B cells and macrophages (Griesemer et al., 2014). As mentioned, AXR comprises both humoral and cellular responses, but the balance is shifted towards a predominant humoral response. Humoral and cellular mechanisms also cause rejection of xenogeneic cells and tissues. Importantly, many molecules and pathways involved are shared by the rejection processes of the different xenografts in spite of relevant particularities for each cell/tissue type.

The humoral arm of the immune response is critical in rejection of vascularized xenografts causing HAR and AHXR in non-human primates. HAR takes place within minutes to hours after xenotransplantation of non-transgenic pig organs through the massive deposition of xenoreactive natural antibodies (XNA) and complement on the donor endothelium resulting in hemorrhage, thrombosis, ischemia and necrosis (Vadori and Cozzi, 2015; Cooper et al., 2015). These XNA are mainly IgM that bind the carbohydrate antigen Gal, which is highly expressed in pig tissues and synthesized by the $\alpha 1,3$-galactosyltransferase ( $\alpha 1,3-\mathrm{GT})$ (Vadori and Cozzi, 2015). Humans produce abundant natural anti-Gal antibodies because they lack a functional $\alpha 1,3-\mathrm{GT}$ and as a result do not express Gal residues. Notably, HAR has been precluded by eliminating Gal from pig tissues by homologous recombination and nuclear transfer/cloning technology, as well as by expression of human complement regulatory proteins (Costa Vallés and Máñez Mendiluce, 2012; McGregor et al., 2012; Cooper et al., 2016). Now, the genetically-modified pig organs transplanted into non-human primate models succumb to AHXR within weeks to months. AHXR involves a strong humoral response with participation of elicited antibodies, complement activation and thrombosis. It is characterized by the presence of an innate immune cellular infiltrate (macrophages and NK cells) and a type-II endothelialcell-activation phenotype that promotes fibrin deposition and intravascular thrombosis (Byrne et al., 2013; Vadori and Cozzi, 2015; Cooper et al., 2015). Understanding the molecular interactions between the human innate immune cells and the xenograft is highly relevant to establish protective interventions (Wang and Yang, 2012). Finally, systemic inflammation is also observed in this setting (Ezzelarab et al., 2015). Thus, the process of AHXR is the most pressing problem in xenotransplantation of solid organs today. Nevertheless, additional carbohydrate antigens recognized by XNA (initially termed non-Gal) have been identified in the pig, and the effect of their elimination (Estrada et al., 2015) remains to be determined in preclinical studies.

The complement system plays a relevant role in the course of any inflammatory response (Carroll and Sim, 2011). In AHXR, the classical pathway triggered by antibody deposition initially generates membrane-bound $\mathrm{C} 4 \mathrm{~b}$ and $\mathrm{C} 3 \mathrm{~b}$ as well as the production of anaphylatoxins $\mathrm{C} 4 \mathrm{a}$ and $\mathrm{C} 3 \mathrm{a}$. $\mathrm{C} 3$ activation will also trigger the alternative pathway, which will further amplify the complement cascade. $\mathrm{C} 4 \mathrm{~b}, \mathrm{C} 3 \mathrm{~b}$ and $\mathrm{C} 3$ breakdown products bind several complement receptors expressed on immune cells promoting B cell activation and phagocytosis (Carroll and Sim, 2011). The three complement-activation pathways, the classical, alternative and lectin pathways, converge in the formation of $\mathrm{C} 5$ convertases that generate the terminal membrane attack complex (C5b-9) and the most potent anaphylatoxin, C5a, leading to cytolysis and inflammation (John et al., 2007; Sacks and Zhou, 2012). Thus, anaphylatoxins cause enhanced vascular permeability, chemotaxis, inflammation, generation of cytotoxic oxygen radicals and histamine release from mast cells. A T-cell-mediated response against pig antigens takes place within days after xenotransplantation. The activation of T cells during xenograft rejection is mediated through the $\mathrm{T}$ cell receptor (TCR) and co-stimulatory signals conserved across species, involving both direct 
Table 1. Potential targets for intervention to genetically modify the pig chondrocytes for use in xenogeneic therapies for cartilage repair.

\begin{tabular}{|l|l|}
\hline Potential therapeutic targets & Function \\
\hline $\begin{array}{l}\text { Gal antigen } \\
\text { Non-Gal antigens }\end{array}$ & Carbohydrate phenotype \\
\hline Human complement regulatory proteins & Complement regulation \\
\hline $\begin{array}{l}\text { Pig VCAM-1 } \\
\text { Pig ICAM-1 }\end{array}$ & Adhesion molecules \\
\hline $\begin{array}{l}\text { Pig IL-6 } \\
\text { Pig IL-8 }\end{array}$ & Cytokines/chemokines secreted by PCs \\
\hline $\begin{array}{l}\text { Human IL-1 } \alpha \\
\text { Human TNF } \alpha\end{array}$ & Cytokines acting on PCs \\
\hline Pig CD86 & Co-stimulatory molecules \\
\hline $\begin{array}{l}\text { Human CD47 } \\
\text { Human CD200 }\end{array}$ & Inhibitory molecules \\
\hline Other & Oxidative stress, apoptosis, cell activation \\
\hline
\end{tabular}

and indirect pathways (Griesemer et al., 2014; Vadori and Cozzi, 2015; Higginbotham et al., 2015). The various immunosuppressive protocols currently available or in advanced development are considered sufficient to control the T-cell immune response against the xenograft (Cooper et al., 2016). In fact, the cellular mechanisms that lead to rejection of cellular grafts are probably very similar and have been successfully controlled in some experiments resulting in long-term survival (i.e. pig pancreatic islets) (Hering et al., 2006). Notably, blockade of the CD40-CD154 co-stimulatory pathway with anti-CD40 antibodies is producing very encouraging results in solid organ xenotransplantation (Higginbotham et al., 2015). Interestingly, the development of cell therapies for immune modulation, such as infusion of expanded regulatory $\mathrm{T}$ cells or mesenchymal stem cells (Griesemer et al., 2014; Higginbotham et al., 2015), seems especially attractive for combinatorial approaches with xenogeneic cellular therapies. In summary, great advances have been made in the xenotransplantation field since the use of the first genetically modified pigs. Although the immunological and non-immunological responses triggered by the xenograft still avert its clinical application, the tools to overcome these barriers are now available. Therefore, key molecules involved in xenograft rejection can be identified and modified to attain long-term engraftment.

\section{Mechanisms of Xenogeneic Cartilage Rejection}

Humoral and cellular responses lead within weeks to months to rejection of pig cartilage transplanted into primates (Stone et al., 1997; Stone et al., 1998). Similar observations have been made in a small animal model (Costa et al., 2003). Although none of the studies reported to date specifically determines the rejection process of xenogeneic chondrocytes transplanted orthotopically into articular defects of non-human primates, the available results are certainly relevant for many cartilage reconstruction applications. The rejection mechanisms of xenogeneic cartilage are highly particular to this tissue and are influenced by intrinsic properties that confer immune privilege. As a start, the fact that cartilage is avascular certainly facilitates its protection from immune attack. Consequently, pig cartilage is not subjected to a fast rejection process equivalent to HAR of vascularized organs. On the contrary, it is slowly rejected by a delayed process, comprising humoral and cellular responses, that progresses over time from the edges towards the inside (Stone et al., 1997; Costa et al., 2003). Our group has been working during the last decade on elucidating the molecular basis of this cartilage rejection process (Costa et al., 2008; Sommaggio et al., 2009; Sommaggio et al., 2012; Sommaggio et al., 2013). Here, we will review this work together with that of others and include new results from our group. A list of potential targets for intervention is provided in Table 1.

\section{Humoral response}

Deposition of human XNA initiates the humoral response towards pig cartilage (Sommaggio et al., 2013). XNA bind to pig chondrocytes (PCs) by mainly recognizing the carbohydrate antigen Gal, ubiquitously present on pig cells (Galili et al., 2013; Vadori and Cozzi, 2015). Early studies were initially conducted to overcome this effect by modifying the pig cartilage following two different strategies. First, Stone et al. (1998) demonstrated that pig meniscus and articular cartilage specimens incubated with $\alpha$-galactosidase resulted in complete removal of the Gal epitopes. Despite this, most animals implanted with $\alpha$-galactosidase-pretreated grafts produced antibodies against other pig cartilage antigens. Notably, the cellular response and the proportion of $\mathrm{T}$ lymphocytes was lower within the $\alpha$-galactosidase-treated xenografts than in untreated cartilage (Stone et al., 1998). Later studies produced similar results when using cartilage from transgenic pigs expressing human $\alpha 1$,2-fucosyltransferase (HT), which leads to a dramatic reduction in Gal expression (Costa et al., 2003). Notably, subcutaneous transplantation of HT cartilage in Gal-deficient mice induced no anti-Gal antibody response and resulted in lower titers of total antipig antibodies when compared to identical mice receiving 


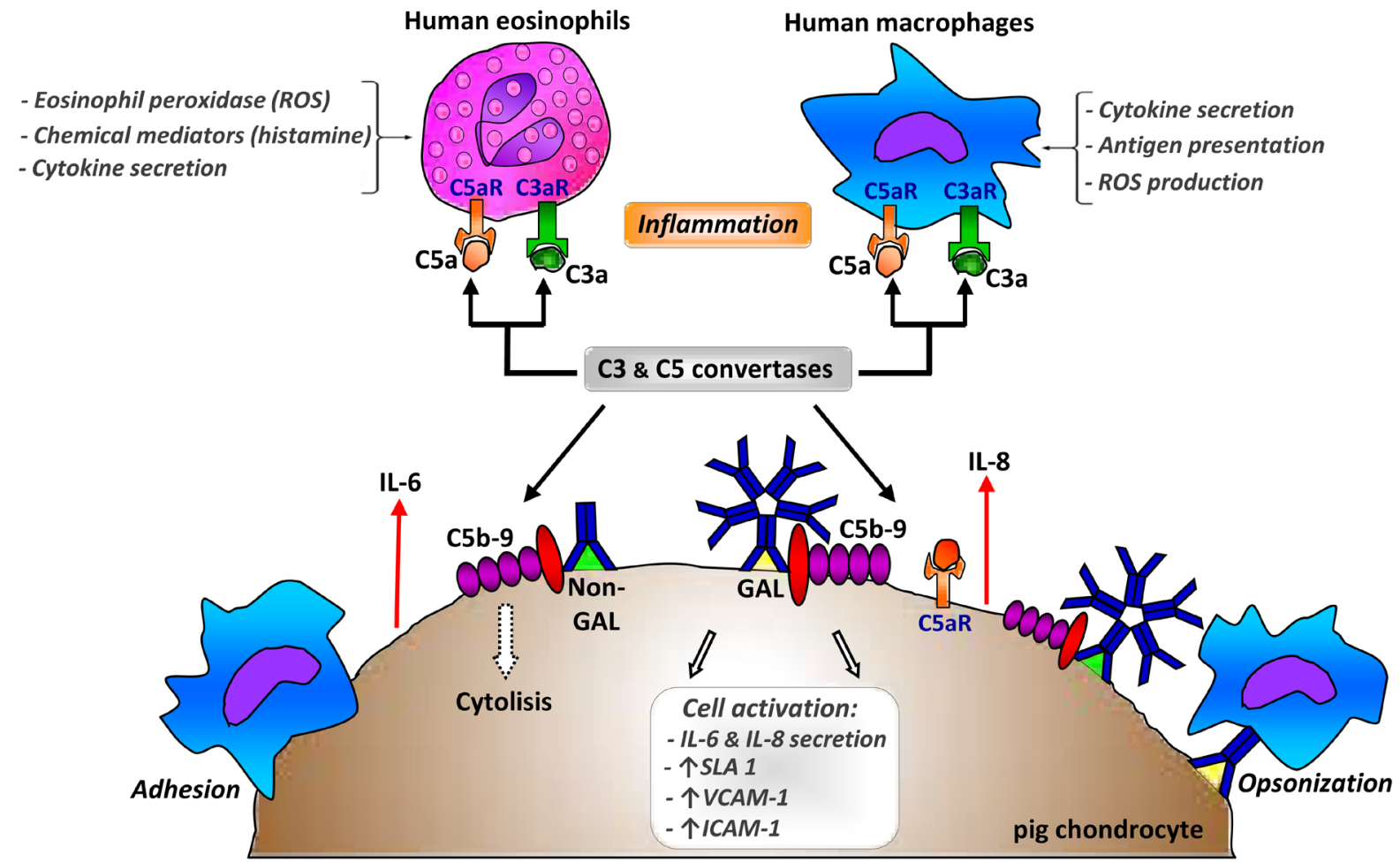

Fig. 2. Scheme of the mechanisms triggered by human antibodies and complement on PCs. Antibody deposition leads to complement activation and opsonization facilitating recognition and phagocytosis by macrophages. The complement cascade ends with the formation of the membrane attack complex (MAC/C5b-9) resulting in cytolysis and cell death of a small proportion of chondrocytes and local anaphylatoxin generation. Most chondrocytes respond to $\mathrm{C} 5 \mathrm{a}$ and C5b-9 by up-regulating activation markers (MHC class I, VCAM-1 and ICAM-1) and secreting IL-6 and IL-8. C3a, C5a and IL-8 promote migration and activation of immune cells that contribute to the inflammatory milieu by releasing multiple inflammatory mediators including TNF $\alpha$ that result in extracellular matrix degradation. The loss of extracellular matrix is enhanced by the up-regulation of catabolic enzymes by IL-6 and C5b-9. C5a and $\mathrm{TNF} \alpha$ contribute to local T cell activation.

control pig cartilage (Costa et al., 2003). Moreover, the HT grafts also presented a reduced cellular immune infiltrate. Thus, the Gal antigen plays a key role in pig cartilage rejection, but the humoral response to the xenogeneic cartilage also involves the reactivity and induction of antinon-Gal antibodies.

The specificity of the anti-non-Gal antibodies reactive to PCs has not been characterized yet. This is pending, as additional carbohydrate antigens recognized by human XNA have been recently identified (Vadori and Cozzi, 2015). Nevertheless, our group has clarified to some extent the mechanisms and effects of total antibody and complement activation on rejection of xenogeneic chondrocytes (Sommaggio et al., 2013; Sommaggio et al., 2015). In particular, we have set up an in vitro model by incubating PCs with up to $40 \%$ human serum and determined complement activation by deposition of complement components on the cell surface and release of complement byproducts. As a result, both the classical and alternative pathways of complement are activated (Sommaggio et al., 2013; Sommaggio et al., 2015), but very little cell death is produced due to an inherent resistance of chondrocytes (Happonen et al., 2012). Instead, exposure of PCs to $20 \%$ human serum leads to PC activation with up-regulation of pig major histocompatibility complex
SLA (for swine leukocyte antigen) class I and vascular cell adhesion molecule 1 (VCAM-1) and intercellular adhesion molecule 1 (ICAM-1), as well as secretion of interleukin-6 (IL-6) and interleukin-8 (IL-8) (Sommaggio et al., 2013). These effects are mainly mediated by C5a generation and formation of the membrane attack complex and promote a pro-inflammatory milieu that is consistent with the cellular immune infiltrates observed in the grafted xenogeneic cartilage which contain predominantly T cells and macrophages (see below for detailed information). This mechanism also explains (at least in part) the reduced cellular response observed in xenografts devoid of Gal antigen as they show diminished antibody reactivity and elicited antibody response of the recipient. The presence of early eosinophilic infiltrates within xenotransplanted cartilage (Stone et al., 1997) may be caused as well by anaphylatoxin release. In fact, we see eosinophils in cartilage grafted in Gal-knockout mice treated with cobra venom factor (which triggers anaphylatoxin release), but not in grafts of mice pretreated with an anti-C5 blocking antibody (Brokaw and Costa, 2015). Remarkably, these findings (summarized in Fig. 2) allow the development of appropriate genetic engineering strategies to counteract the effects of antibody and complement, as recently described by our group (Sommaggio et al., 2015). All this information 
a

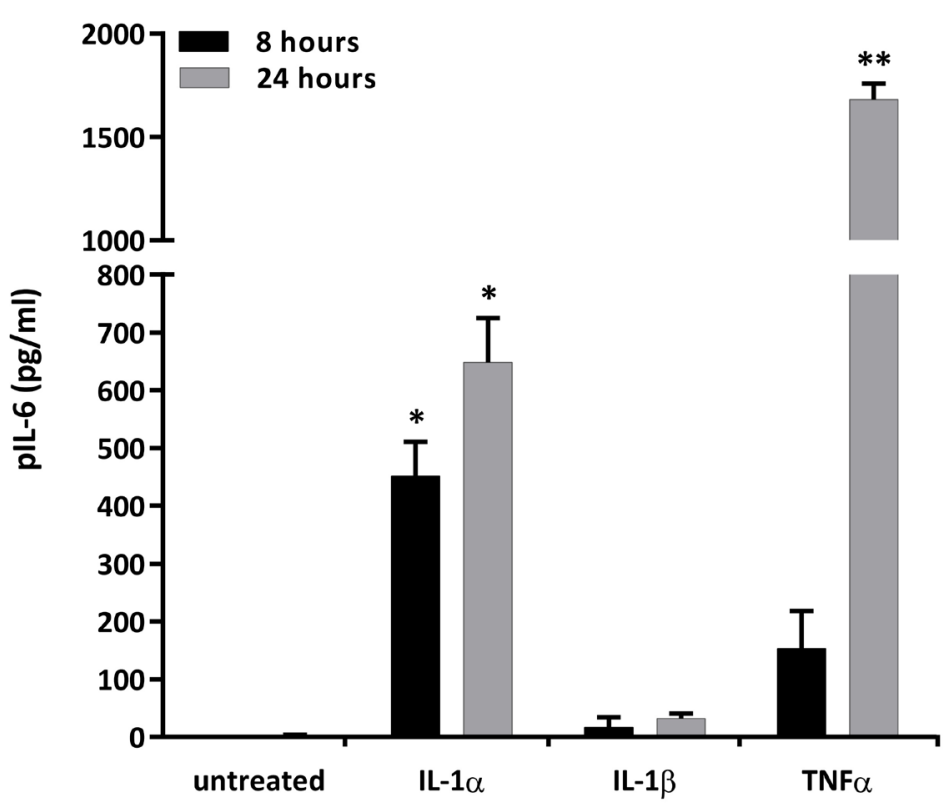

b

Fig. 3. Secretion of IL-6 and IL- 8 by PCs in response to pro-inflammatory cytokines. PCs were left untreated or pre-treated with the indicated cytokines for $8 \mathrm{~h}$ or $24 \mathrm{~h}$ and pIL-6 (a) and pIL-8 (b) were measured in culture supernatants by ELISA. The mean \pm standard error of the mean of the 3 independent experiments is shown. Significant differences were observed by Student $t$ test between untreated and cytokine-stimulated PCs when indicated, ${ }^{\mathrm{a}} p \leq 0.05,{ }^{\mathrm{b}} p<0.01$.

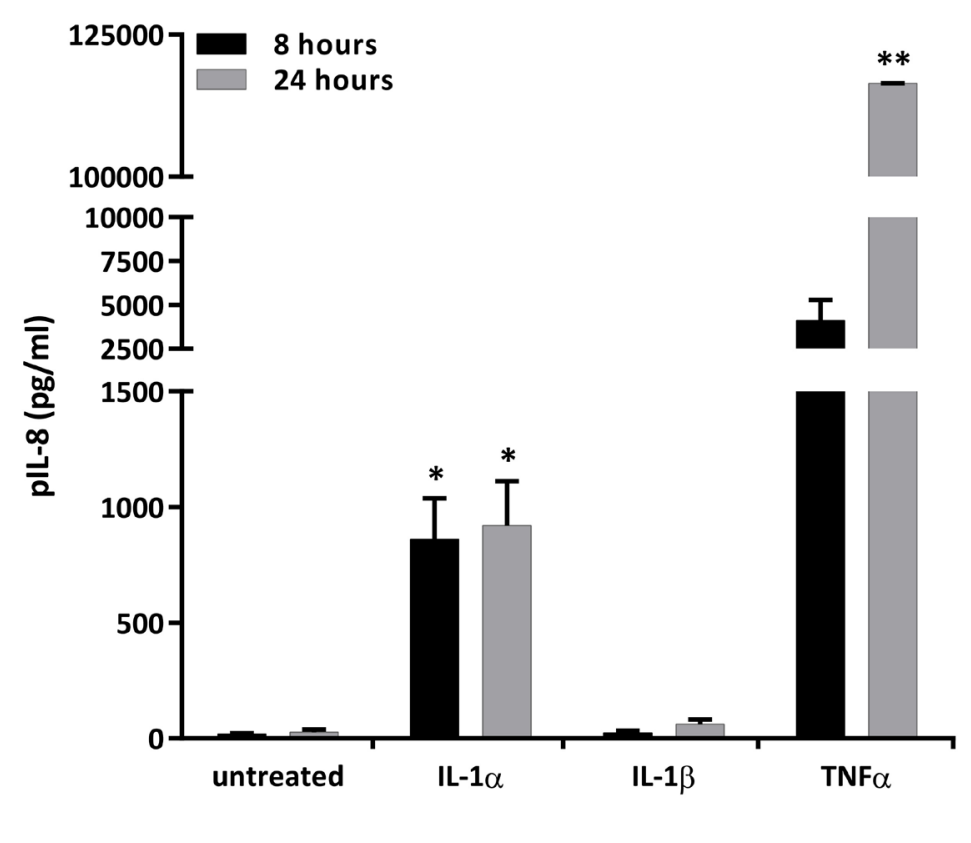

is highly valuable for understanding the contribution of the antibody response to rejection of avascular tissues, but it also has important implications for solid organ xenografts in which inflammation has been described (Ezzelarab et al., 2015).

\section{Cellular immune response}

Pig cartilage xenografts retrieved from a suprapatellar pouch after transplantation in cynomolgus monkeys show extensive cellular immune infiltrates in the graft periphery (Stone et al., 1997). At one month post-transplantation, infiltrates of eosinophils or a mixture of eosinophils and macrophages are seen. After two months, the cellular immune infiltrates contain about $80-90 \%$ of T cells (half $\mathrm{CD}^{+}$and half $\mathrm{CD}^{+}$) and $10-20 \%$ of macrophages together with some plasma cells, a few eosinophils and giant cells (Stone et al., 1997). In a similar way to other pig xenografts, such as pancreatic islets and skin, both $\mathrm{CD} 4^{+}$and $\mathrm{CD} 8^{+} \mathrm{T}$ cells contribute to rejection of xenogeneic cartilage. Thus, systemic depletion of $\mathrm{CD}^{+} \mathrm{T}$ cells delays rejection in a pig-to-mouse cartilage transplant model by reducing $\mathrm{T}$ cells and macrophages in the xenograft (Costa et al., 2003). However, the remaining mononuclear cellular infiltrate slowly rejects the graft. In general, the cellular immune response plays a critical role in rejection of cell-based xenografts. We have been investigating the underlying mechanisms with the conviction that a good understanding of the rejection process and the molecules involved will allow the development of effective counteractive genetic engineering strategies and lead to clinical success.

Our basic material for these types of studies is the PC, which we isolate from either articular or costal pig cartilage (hyaline in both cases) following well described procedures (Costa et al., 2003; Sommaggio et al., 2009). These PCs 
can be kept in monolayer culture for a few passages while maintaining expression profiles characteristic of cartilage (Sommaggio et al., 2009). Furthermore, PCs can be cryopreserved at low passage with good recoveries, which is highly relevant for future developments. Taking into account that many cytokines and chemokines function across species, PCs themselves are capable of contributing to the pro-inflammatory response in a xenotransplant setting. In a similar way to the effects of complement activation on PCs, human interleukin-1 $\alpha$ (hIL-1 $\alpha)$ and human tumor necrosis factor $\alpha$ (hTNF $\alpha$ ) (mainly produced by myeloid and NK cells) do not lead to PC cell death (Sommaggio et al., 2009), but induce a pro-inflammatory phenotype in PCs which respond by releasing pig IL-6 and IL-8 (Fig. 3a,b). Our findings are in agreement with numerous studies that describe how human chondrocytes secrete multiple cytokines and chemokines during arthritis and in response to cytokines, a process that is at least partially mediated by nuclear factor- $\kappa \mathrm{B}(\mathrm{NF}-\kappa \mathrm{B})$ (De Ceuninck et al., 2004; Pulai et al., 2005; Kapoor et al., 2011). Importantly, human IL-1 $\beta$ (hIL-1 $\beta$ ), hTNF $\alpha$ and possibly IL-6 participate in cartilage degradation by reducing anabolic activities and simultaneously upregulating matrix metalloproteinases and aggrecanases, as well as other inflammatory mediators (Kapoor et al., 2011; Sommaggio et al., 2013; Schett et al., 2016). In addition, IL-8 and other chemokines will amplify theses effects by attracting more immune cells and enhancing catabolic activities (Kapoor et al., 2011; Sommaggio et al., 2013).

Our initial characterization of PCs led us additionally to determine the cell surface expression of the SLA, adhesion and co-stimulatory molecules on PCs in resting and cytokine-stimulated conditions (Sommaggio et al., 2009). We confirmed the constitutive and regulated expression of SLA class I, but not of SLA-II which remained undetectable in all conditions assessed. Thus, SLA-I is strongly up-regulated by a 24 -hour treatment with hTNF $\alpha$ or hIL- $1 \alpha$, although hIL- $1 \beta$ has no effect at this level. The adhesion molecule VCAM-1 is expressed at low levels on resting PCs, whereas ICAM-1 displays higher cell surface expression. Notably, both molecules are dramatically increased by hTNF $\alpha$ and hIL- $1 \alpha$. In contrast, pig E-selectin was not detected in any of the conditions assayed. Regarding co-stimulatory molecules, the potent CD86 (also known as B7.2) is expressed at moderate levels, whereas CD80 and CD40 are barely detected on the cell surface. Furthermore, none of these co-stimulatory molecules were reported to be up-regulated under the cytokine-stimulated conditions tested (hTNF $\alpha$, hIL-1 $\alpha$ and hIL-1 $\beta$ ). This lack of reactivity cannot be attributed to defective reagents during these determinations, as positive signals were obtained with porcine aortic endothelial cells (PAECs). In fact, the differences observed between PCs and PAECs are highly relevant as all these adhesion and co-stimulatory molecules promote leukocyte adhesion and together with SLA mediate direct activation of different subsets of human T cells (Murray et al., 1994; Rollins et al., 1994). Furthermore, these can also contribute to the recognition of pig cells by human natural killer (NK) cells (Costa et al., 2002; Sommaggio et al., 2012).

\section{Molecular bases of T-cell responses}

In transplantation, the $\mathrm{T}$ cells can be activated by either the direct pathway ( $\mathrm{T}$ cells recognizing the donor cells) or the indirect pathway (through the host antigen presenting cells that have processed and present the donor antigens). At the molecular level, T-cell activation is triggered by the interaction of the $\mathrm{T}$ cell receptor (TCR) with the peptide-loaded MHC with the help of co-stimulatory signals. The capacity of the human TCRs to directly recognize the SLA and activate human $\mathrm{CD}^{+}$and $\mathrm{CD}^{+}$ $\mathrm{T}$ cells has been demonstrated using PAECs as antigen presenting cells (Murray et al., 1994; Rollins et al., 1994). The sole expression of SLA class I on PCs sets the basis for allowing a direct activation of human $\mathrm{CD} 8^{+}$ $\mathrm{T}$ cells when co-stimulation is available. In PAECs, pig CD86 is known to provide a strong co-stimulatory signal for T cell activation and survival (Maher et al., 1996). Importantly, CD86 binds the T-cell activating receptor CD28, but also the tolerogenic receptor CTLA-4 (cytotoxic T-lymphocyte-associated protein 4, CD152) expressed on activated and regulatory T cells. By using specific blocking monoclonal antibodies, we have established that CD86 on PCs provides a key co-stimulatory signal for activation of human T cells, whereas pig VCAM-1 plays a secondary role (Sommaggio et al., 2009). On the contrary, the poorly expressed pig CD80 and/or CD40 are not likely to play a critical role in this setting. We infer this information taking into account the dramatic drop in T cell response after CD86 blockade ( $80 \%$ reduction in IL-2 secretion in the co-culture assay), the participation of pig VCAM-1 and the probable contribution of pig ICAM-1. We summarize this information in a scheme (Fig. 4a). Interestingly, the negligible CD40 expression on PCs probably represents an advantage over PAECs. Engagement of pig CD40 on PAECs leads to cell activation (Rushworth et al., 2001). In addition, pig CD40 may well participate in the direct activation of human $\mathrm{T}$ cells as an anti-hCD154 mAb displays an inhibitory effect in co-culture experiments (Tadaki et al., 2000). Therefore, pig CD86 is a target for intervention in the development of less immunogenic PCs and its blockade through genetic engineering is expected to have a beneficial effect. Depending on the strategy chosen, deletion of pig CD86, expression of CTLA4-Ig or both, different outcomes will be expected. Note that interfering only with pig CD86 will not control the indirect pathway of $\mathrm{T}$ cell activation which is responsible for the important contribution of $\mathrm{CD}^{+} \mathrm{T}$ cells.

\section{Molecular bases of NK cell responses}

NK cells play a role in transplant rejection with a more prominent contribution in the case of xenografts (Kitchens et al., 2006; Resch et al., 2015). NK cells are lymphoid cells that recognize and kill a variety of neoplastic, virus-infected, and non-self target cells through release of perforin and granzyme B (Vivier et al., 2008). As evidence of their contribution to xenograft failure, NK cells are found in pig organs perfused with human blood and in rejecting grafts in pig-to-baboon xenotransplantation models (Inverardi and Pardi, 1994; Itescu et al., 1998). In vitro experiments show that human NK cells lyse PAECs 


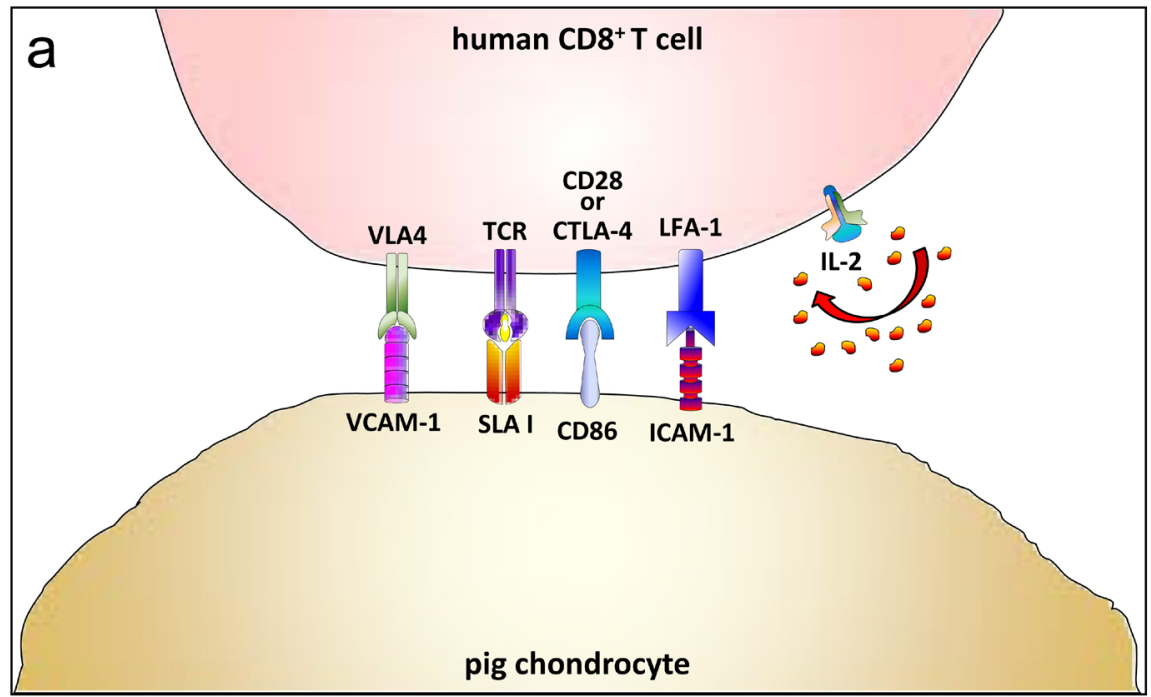

Fig. 4. Key molecules involved in the interaction of human $\mathrm{T}$ cells and NK cells with PCs. (a) Human $\mathrm{T}$ cells are recruited to the xenograft and specific $\mathrm{CD}^{+} \mathrm{T}$ cell clones are activated through direct recognition of the pig SLA/ peptide complex and pig CD86 for hIL-2 secretion and clonal expansion. (b) Recruited human NK cells are activated through direct recognition of unidentified pig ligands with activating NK cell receptors, as well as by xenoantibody deposition that results in NK cell-mediated killing of chondrocytes.

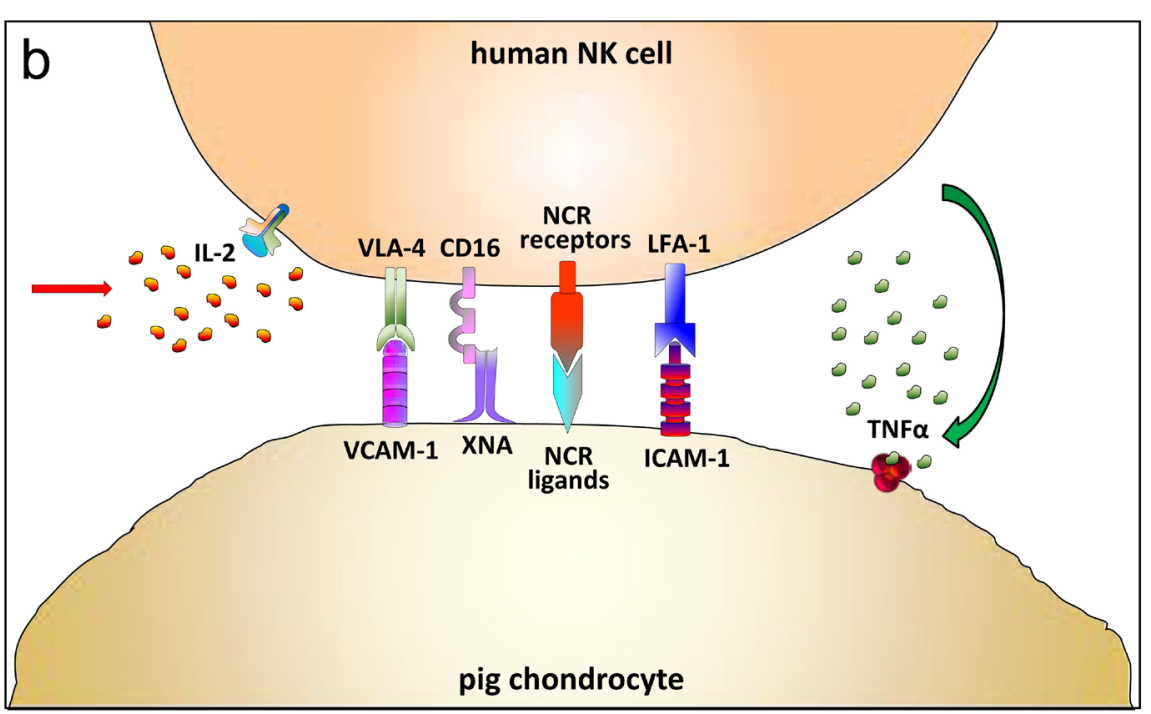

due to the incapacity of SLA I molecules to signal through human NK cell inhibitory receptors (Sullivan et al., 1997). Thus, NK cells can lyse pig cells both directly and by ADCC in a very efficient manner (Baumann et al., 2004; Forte et al., 2005).

NK cells could also contribute to rejection of xenogeneic avascular tissues such as cartilage. Although no specific staining for these cells has been conducted in histopathological studies of retrieved cartilage xenografts, NK cells could be part of the lymphocytic infiltrates already described. In fact, results from cell-based assays show that human NK cells have the capacity to kill PCs under specific conditions. An initial and essential step in NK cell cytotoxicity is adhesion to target cells. Our group has shown that resting human NK cells display only weak adhesion to PCs, but exposure of NK cells to IL-2 or stimulation of PCs with hTNF $\alpha$ or hIL-1 $\alpha$ increases adhesion (Sommaggio et al., 2012). We elucidated that, in a similar way to PAECs, adhesion of human NK cells to PCs relies mainly on VLA-4-VCAM-1 and on LFA-1ICAM-1 interactions (Sommaggio et al., 2012). Notably, PCs show susceptibility to NK cell-mediated cytotoxicity in correlation with the levels of adhesion. Accordingly, ligands for natural cytotoxicity receptors (NCR) were detected on PCs using fusion proteins of human NCR and flow cytometry. By using specific blocking antibodies, NKp44, NKG2D and NKp46 were identified as responsible for triggering NK-cell-mediated cytotoxicity against PCs (Sommaggio et al., 2012). Moreover, we observed upregulation of ligands for NKp44 and NKp30 when the chondrocytes were stimulated with $\mathrm{hTNF} \alpha$ relative to untreated PCs. Thus, cytokine stimulation leads to elevated levels of adhesion molecules and NCR ligands on PCs that correlates with higher susceptibility to lysis mediated by human NK cells under these conditions. We summarize this knowledge in Fig. 4 b.

Engagement of CD16, a low affinity Fc receptor expressed on NK cells, suffices to induce efficient lysis of pig endothelial cells by ADCC in the absence of NCRmediated signaling (Forte et al., 2005). Likewise, our work further demonstrated that human NK cells kill PCs by ADCC (Fig. 4b) (Sommaggio et al., 2012). Nevertheless, we also found that PCs are more resistant to NK cellmediated cytotoxicity than PAECs even in the presence of XNA. Thus, it is highly likely that the benefit described after removal of Gal antigen in cartilage implants in 


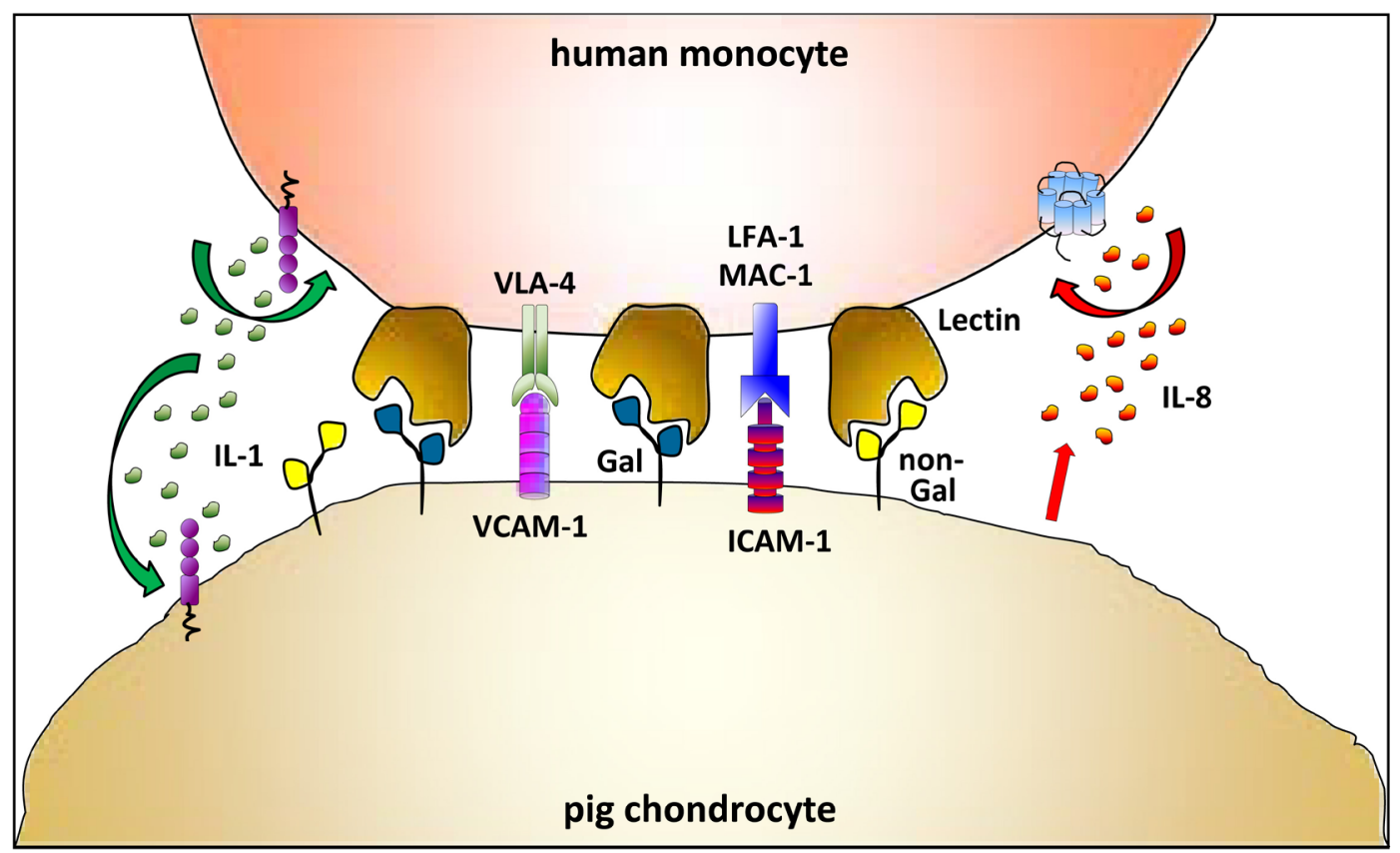

Fig. 5. Key molecules involved in the interaction of human monocytes with PCs. We propose that the PCs initiate the xenogeneic cellular immune response by binding human monocytes/macrophages and dendritic cells through the Gal antigen and/or other carbohydrates together with adhesion molecules leading to cell activation and cytokine release by both human leukocytes and PCs. Cytokines such as hIL- $1 \alpha$ and hIL- $1 \beta$ further amplify this process by stimulating the expression of adhesion molecules and cytokine/chemokine release.

previous reports was in part due to a reduction in ADCC. These results lead us to predict that a carbohydrateremodeling approach that substantially reduces human XNA reactivity will have a major impact in protecting PCs from NK cell-mediated lysis. Additional modifications that target adhesion and/or co-stimulatory molecules in PCs would be expected to further protect from this rejection pathway.

Molecular bases of monocyte and macrophage responses Synovial macrophages play a major role in the pathogenesis of arthritis (Kennedy et al., 2011). Moreover, monocytes and macrophages are critical effectors in acute xenograft rejection (Li et al., 2009). As mentioned earlier in this review, the cellular infiltrates in cartilage xenografts of a pig-to-cynomolgus monkey model contain up to $20 \%$ macrophages (Stone et al., 1997). Macrophages are also found to be major contributors to rejection of human chondrocytes implanted with hydrogel into full-thickness chondral defects (as MACI) located in femoral chondyles of minipigs (Niemietz et al., 2014). Despite the limited preclinical value of this xenogeneic combination, the work of Niemietz et al. (2014) is the first publication describing rejection of xenogeneic chondrocytes in an animal model of orthotopic transplantion for articular cartilage repair.

Our team has been working on elucidating some of the mechanisms of rejection of xenogeneic chondrocytes led by myeloid cells. As for NK cells, adhesion is an initial step for monocytes/macrophages to generate an immune response against PCs. In this regard, we have demonstrated that pig VCAM-1 is a key molecule for the binding of U937 cells (human monoblastic cell line) to cytokine- activated PCs (Sommaggio et al., 2009). As pig ICAM-1 is the adhesion molecule most expressed on resting PCs and binds human LFA-1 and MAC-1, it is most probably responsible for adhesion of human monocytes to PCs in both un-stimulated and stimulated conditions. Nonetheless, additional receptors are likely contributing to recognize the pig cells as foreign by human monocytes/macrophages. A lectin-dependent pathway could be one of the mechanisms by which host monocytes specifically recognize xenografts in an antibody and complement independent manner. Galectin-3, a lectin expressed by various cells including human monocytes and macrophages, has been reported to interact directly with the Gal antigen (Jin et al., 2006). Human NKRP1A (CD161), a C-type lectin inhibitory receptor expressed on NK cells, peripheral blood monocytes and dendritic cells, also binds to Gal epitope (Christiansen et al., 2006). Despite contradictions between the various studies available on the participation of Gal in this process (Schneider and Seebach, 2008), data from our group further shows that adhesion of U937 cells to HT-transgenic PCs is reduced relative to controls in both resting and hTNF $\alpha$-stimulated conditions (Costa et al., 2008). Therefore, although a carbohydrate-mediated recognition probably contributes to baseline adhesion and initiation of an immune response, we expect that the highly-inducible pig molecules VCAM-1 and ICAM-1 are critical for adhesion to PC after cytokine stimulation (Fig. 5). Xenogeneic antibodies and complement will provide additional activation signals through their corresponding receptors unless these pathways are counteracted by genetic engineering strategies (Sommaggio et al., 2015). A summary of their effect is included in Fig. 2. 


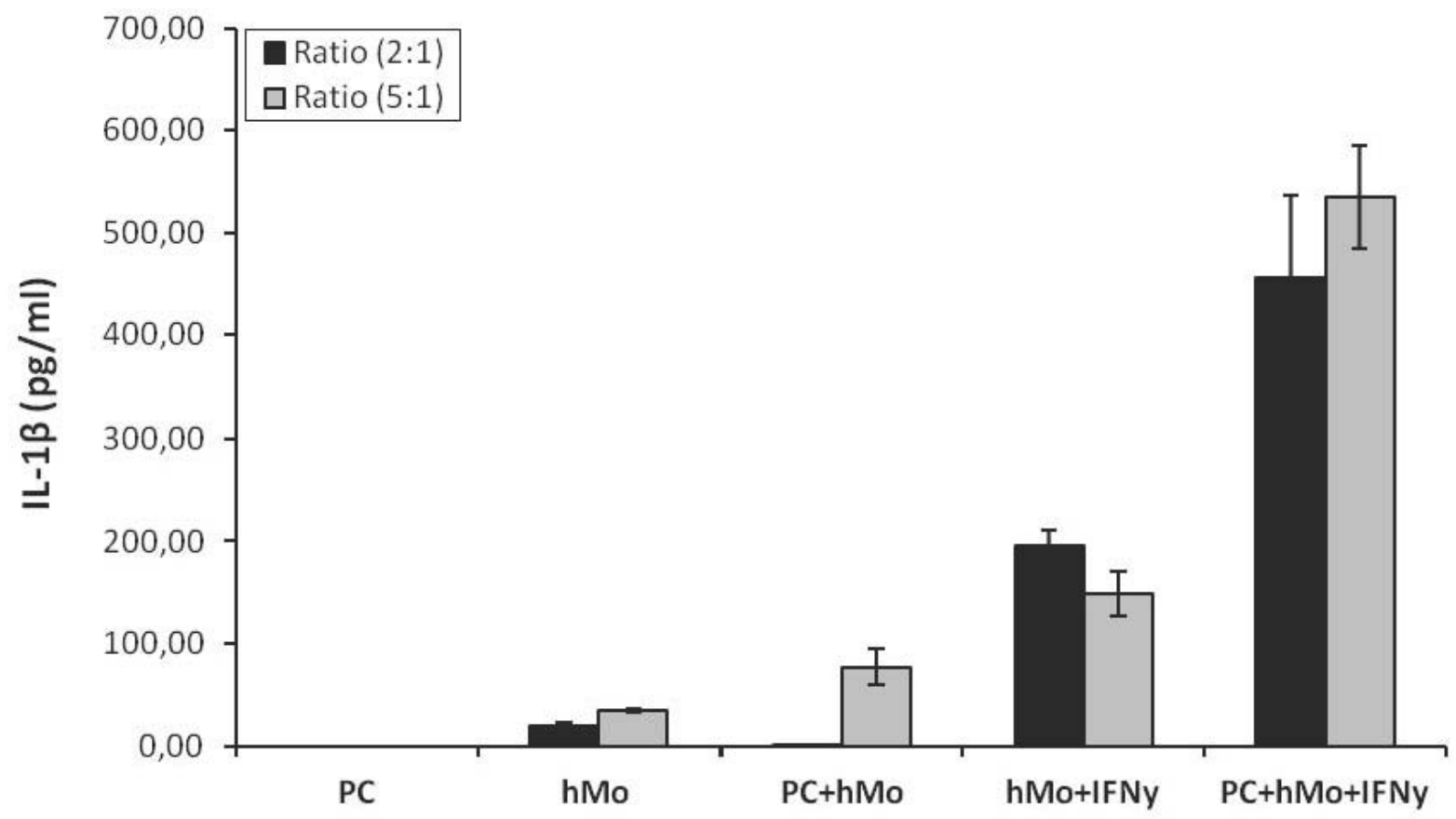

Fig. 6. Response of human monocytes to PCs. Human monocytes (hMo) isolated from preripheral blood of healthy donors by magnetic negative selection were co-cultured for $24 \mathrm{~h}$ with resting PCs (PC) at a 2:1 and 5:1 effector/ target ratio. The same quantity of monocytes was cultured alone for each donor and experiment as control. Human IFN $\gamma$ was added to selected wells at $20 \mathrm{ng} / \mathrm{mL}$ for the duration of the culture. Human IL-1 $\beta$ was chosen for the readout of the monocyte response and was measured in collected supernatants by ELISA. Mean \pm standard deviation of duplicates of a representative experiment of 3 independent experiments is shown.

Regarding the effects of such recognition, initial studies showed that co-culture of U937 with cytokineactivated PCs lead to an increase in human IL-8 secretion (Sommaggio et al., 2009). We are now generating new data using isolated human monocytes co-cultured with PCs that further support this observation. In particular, we have measured hIL-1 $\beta$ because of its relevance in cartilage inflammation and disease (Schett et al., 2016). The data indicate that PCs alone or in the presence of interferon $\gamma$ (IFN $\gamma$ ) stimulate hIL-1 $\beta$ secretion by human monocytes (Fig. 6). Thus, we foresee the need to prevent these inflammatory reactions by designing appropriate genetic modifications of the pig source cartilage that prevent the activation of monocytes and macrophages during the early stages of recognition. A critical molecular target when pursuing the inhibition of the monocytes/macrophage response to xenogeneic pig cells is CD47 (Ide et al., 2007). CD47 is a ubiquitous ligand for the signal-regulatory protein- $\alpha$ (SIRP- $\alpha)$ receptor expressed on macrophages. Engagement of SIRP- $\alpha$ provides inhibitory signals to macrophages that prevent the phagocytosis of autologous cells. Notably, pig CD47 does not induce SIRP- $\alpha$ tyrosine phosphorylation in human macrophage-like cells (Ide et al., 2007). Therefore, the inhibitory signal is missing in this xenogeneic combination. Considering that this is a concept that applies to all pig cells, transgenic expression of human CD47 on PCs should be considered as well for controlling the immune response of human monocytes in this setting. Other inhibitory molecules for myeloid cells, such as CD200 (Barclay et al., 2002), may be of use as well.

\section{Conclusions}

A variety of therapeutic approaches are available for the treatment of articular cartilage defects, but none is currently completely satisfactory. New tissue-engineering therapies are also needed for some large cartilage defects affecting the joint and other cartilage types. We propose the use of genetically-modified PCs as a new cell source that can provide advantages and be applied for the development of multiple cell- and tissue-engineering-based therapies. We have identified antibodies and complement, immune cells, cell-surface molecules and cytokines that contribute to the xenogeneic immune response triggered by PCs. Because of their strong activity, pig CD86 and TNF $\alpha$ are potential targets for intervention for the development of clinical applications based on xenotransplantation of PCs. Their specific blockade may help avert the cellular immune response against PCs. Notably, human NK cells and monocytes recognize $\mathrm{PCs}$ as foreign and their activation surely contributes to rejection, pointing out the need to cover these aspects as well. Thus, the combination of cellsurface carbohydrate remodeling to reduce XNA deposition with control of complement activation and targeting adhesion and/or co-stimulation might be a promising strategy. The time has come to start developing all these genetic engineering approaches and test them in preclinical models to assess the real potential of this concept. 


\section{Acknowledgments}

We gratefully acknowledge JA Collado for his technical assistance and A Gimeno-Sandig for providing pig joints and ribs. This research line has been funded by Fundación de Investigación Médica Mútua Madrileña (338/05), Fundació La Marató de TV3 (2007-082430), Ministerio de Educación y Ciencia (SAF2008-00499) and Ministerio de Ciencia e Innovación - Instituto de Salud Carlos III (PI11/02179), all granted to CC, and cofunded by FEDER funds - a way to build Europe. CC was supported by the Ramón y Cajal program from Ministerio de Ciencia y Tecnología (Spain) and IDIBELL, and MU-H by an IDIBELL fellowship. RS benefited from a one-year fellowship from Fundació Catalana de Trasplantament. We wish to confirm that there are no known conflicts of interest associated with this publication and there has been no significant financial support for this work that could have influenced its outcome.

\section{References}

Arend WP, Firestein GS (2012) Pre-rheumatoid arthritis: predisposition and transition to clinical synovitis. Nat Rev Rheumatol 8: 573-586.

Barclay AN, Wright GJ, Brooke G, Brown MH (2002) CD200 and membrane protein interactions in the control of myeloid cells. Trends Immunol 23: 285-290.

Basad E, Wissing FR, Fehrenbach P, Rickert M, Steinmeyer J, Ishaque B (2015) Matrix-induced autologous chondrocyte implantation (MACI) in the knee: clinical outcomes and challenges. Knee Surg Sports Traumatol Arthrosc 23: 3729-3735

Baumann BC, Forte P, Hawley RJ, Rieben R, Schneider MK, Seebach JD (2004) Lack of galactose-alpha-1,3galactose expression on porcine endothelial cells prevents complement-induced lysis but not direct xenogeneic NK cytotoxicity. J Immunol 172: 6460-6467.

Berta Á, Duska Z, Tóth F, Hangody L (2015) Clinical experiences with cartilage repair techniques: outcomes, indications, contraindications and rehabilitation. Eklem Hastalik Cerrahisi 26: 84-96.

Brokaw JL, Costa C (2015) In contrast to anti-C5 therapy, cobra venom factor does not prevent rejection of xenogeneic cartilage in mice. Transplant Proc 47: 2397 2399.

Byrne GW, Azimzadeh AM, Ezzelarab M, Tazelaar HD, Ekser B, Pierson RN, Robson SC, Cooper DK, McGregor CG (2013) Histopathologic insights into the mechanism of anti-non-Gal antibody-mediated pig cardiac xenograft rejection. Xenotransplantation 20: 292-307.

Carroll MV, Sim RB (2011) Complement in health and disease. Adv Drug Deliv Rev 63: 965-975.

Catrina AI, Joshua V, Klareskog L, Malmström V (2016) Mechanisms involved in triggering rheumatoid arthritis. Immunol Rev 269: 162-174.

Christiansen D1, Mouhtouris E, Milland J, Zingoni A, Santoni A, Sandrin MS (2006) Recognition of a carbohydrate xenoepitope by human NKRP1A (CD161). Xenotransplantation 13: 440-446.
Cooper DK, Ekser B, Tector AJ (2015) Immunobiological barriers to xenotransplantation. Int J Surg 23: 211-216.

Cooper DK, Ekser B, Ramsoondar J, Phelps C, Ayares D (2016) The role of genetically engineered pigs in xenotransplantation research. J Pathol 238: 288-299.

Costa Vallés C, Máñez Mendiluce R (2012) Transgenic organs and xenotransplants. Adv Exp Med Biol 741: 73-88.

Costa C, Barber DF, Fodor WL (2002) Human NK cellmediated cytotoxicity triggered by CD86 and Gal alpha $1,3-\mathrm{Gal}$ is inhibited in genetically modified porcine cells. J Immunol 168: 3808-3816.

Costa C, Brokaw JL, Wang Y, Fodor WL (2003) Delayed rejection of porcine cartilage is averted by transgenic expression of $\alpha 1,2$-fucosyltransferase. FASEB J 17: 109-111.

Costa C, Brokaw JL, Fodor WL (2008) Characterization of cartilage from $\mathrm{H}$-transferase transgenic pigs. Transplant Proc 40: 554-556.

Cucchiarini M, Madry H, Guilak F, Saris DB, Stoddart MJ, Koon Wong M, Roughley P (2014) A vision on the future of articular cartilage repair. Eur Cell Mater 27: 1216.

De Ceuninck F, Dassencourt L, Anract P (2004) The inflammatory side of human chondrocytes unveiled by antibody microarrays. Biochem Biophys Res Commun 323: 960-969.

Dearnley, PA (1999) A review of metallic, ceramic and surface-treated metals used for bearing surfaces in human joint replacements. Proc Inst Mech Eng H 213: 107-135.

Ekser B, Ezzelarab M, Hara H, van der Windt DJ, Wijkstrom M, Bottino R, Trucco M, Cooper DK (2012) Clinical xenotransplantation: the next medical revolution? Lancet 379: 672-683.

Ekser B, Cooper DK, Tector AJ (2015) The need for xenotransplantation as a source of organs and cells for clinical transplantation. Int J Surg 23: 199-204.

Estrada JL, Martens G, Li P, Adams A, Newell KA, Ford ML, Butler JR, Sidner R, Tector M, Tector J (2015) Evaluation of human and non-human primate antibody binding to pig cells lacking GGTA1/CMAH/ $\beta 4$ GalNT2 genes. Xenotransplantation 22: 194-202.

Ezzelarab MB, Ekser B, Azimzadeh A, Lin CC, Zhao Y, Rodriguez R, Echeverri GJ, Iwase H, Long C, Hara H, Ayares D, Pierson RN, Thomson AW, Cooper DK (2015) Systemic inflammation in xenograft recipients precedes activation of coagulation. Xenotransplantation 22: 32-47.

Fabre D, Kolb F, Fadel E, Mercier O, Mussot S, Le Chevalier T, Dartevelle P (2013) Successful tracheal replacement in humans using autologous tissues: an 8-year experience. Ann Thorac Surg 96: 1146-1155.

Forte P, Lilienfeld BG, Baumann BC, Seebach JD (2005) Human NK cytotoxicity against porcine cells is triggered by NKp44 and NKG2D. J Immunol 175: 54635470 .

Fulco I, Miot S, Haug MD, Barbero A, Wixmerten A, Feliciano S, WolfF, Jundt G, Marsano A, Farhadi J, Heberer M, Jakob M, Schaefer DJ, Martin I (2014) Engineered autologous cartilage tissue for nasal reconstruction after tumour resection: an observational first-in-human trial. Lancet 384: 337-346. 
Galili U (2013) Discovery of the natural anti-Gal antibody and its past and future relevance to medicine. Xenotransplantation 20: 138-147.

Gillogly SD, Wheeler KS (2015) Autologous chondrocyte implantation with collagen membrane. Sports Med Arthrosc 23: 118-124.

Glyn-Jones S, Palmer AJ, Agricola R, Price AJ, Vincent TL, Weinans H, Carr AJ (2015) Osteoarthritis. Lancet 386: 376-387.

Gracitelli GC, Meric G, Pulido PA, McCauley JC, Bugbee WD (2015) Osteochondral allograft transplantation for knee lesions after failure of cartilage repair surgery. Cartilage 6: 98-105.

Griesemer A, Yamada K, Sykes M (2014) Xenotransplantation: immunological hurdles and progress toward tolerance. Immunol Rev 258: 241-258.

Happonen KE, Fürst CM, Saxne T, Heinegård D, Blom AM (2012) PRELP protein inhibits the formation of the complement membrane attack complex. J Biol Chem 287: 8092-8100.

Hering BJ, Wijkstrom M, Graham ML, Hårdstedt M, Aasheim TC, Jie T, Ansite JD, Nakano M, Cheng J, Li W, Moran K, Christians U, Finnegan C, Mills CD, Sutherland DE, Bansal-Pakala P, Murtaugh MP, Kirchhof N, Schuurman HJ (2006) Prolonged diabetes reversal after intraportal xenotransplantation of wild-type porcine islets in immunosuppressed nonhuman primates. Nat Med 12: 301-303.

Higginbotham L, Ford ML, Newell KA, Adams AB (2015) Preventing T cell rejection of pig xenografts. Int J Surg 23: 285-290.

Horas U, Pelinkovic D, Herr G, Aigner T, Schnettler R (2003) Autologous chondrocyte implantation and osteochondral cylinder transplantation in cartilage repair of the knee joint. A prospective, comparative trial. J Bone Joint Surg Am 85: 185-192.

Ide K, Wang H, Tahara H, Liu J, Wang X, Asahara T, Sykes M, Yang YG, Ohdan H (2007) Role for CD47-SIRPalpha signaling in xenograft rejection by macrophages. Proc Natl Acad Sci USA 104: 5062-5066.

Inverardi L, Pardi R (1994) Early events in cellmediated recognition of vascularized xenografts: cooperative interactions between selected lymphocyte subsets and natural antibodies. Immunol Rev 141: 71-93.

Itescu S, Kwiatkowski P, Artrip JH, Wang SF, Ankersmit J, Minanov OP, Michler RE (1998) Role of natural killer cells, macrophages, and accessory molecule interactions in the rejection of pig-to-primate xenografts beyond the hyperacute period. Hum Immunol 59: 275-286.

Jin R, Greenwald A, Peterson MD, Waddell TK (2006) Human monocytes recognize porcine endothelium via the interaction of galectin 3 and alpha-GAL. J Immunol 177: 1289-1295.

John T, Stahel PF, Morgan SJ and Schulze-Tanzil G (2007) Impact of the complement cascade on posttraumatic cartilage inflammation and degradation. Histol Histopathol 22: 781-790.

Kapoor M, Martel-Pelletier J, Lajeunesse D, Pelletier JP, Fahmi H (2011) Role of proinflammatory cytokines in the pathophysiology of osteoarthritis. Nat Rev Rheumatol 7: 33-42.
Kennedy A, Fearon U, Veale DJ, Godson C (2011) Macrophages in synovial inflammation. Front Immunol 2: 52 .

Kitchens WH, Uehara S, Chase CM, Colvin RB, Russell PS, Madsen JC (2006) The changing role of natural killer cells in solid organ rejection and tolerance. Transplantation 81: 811-817.

Lai L, Kolber-Simonds D, Park KW, Cheong HT, Greenstein JL, Im GS, Samuel M, Bonk A, Rieke A, Day BN, Murphy CN, Carter DB, Hawley RJ, Prather RS (2002) Production of alpha-1,3-galactosyltransferase knockout pigs by nuclear transfer cloning. Science 295: 1089-1092.

Långsjö TK, Vasara AI, Hyttinen MM, Lammi MJ, Kaukinen A, Helminen HJ, Kiviranta I (2010) Quantitative analysis of collagen network structure and fibril dimensions in cartilage repair with autologous chondrocyte transplantation. Cells Tissues Organs 192: 351-360.

Lee YH, Suzer F, Thermann H (2014) Autologous matrix-induced chondrogenesis in the knee: a review. Cartilage 5: 145-153.

Li S, Waer M, Billiau AD (2009) Xenotransplantation: role of natural immunity. Transpl Immunol 21: 70-74.

Madeira C, Santhagunam A, Salgueiro JB, Cabral JM (2015) Advanced cell therapies for articular cartilage regeneration. Trends Biotechnol 33: 35-42.

Maher SE, Karmann K, Min W, Hughes CC, Pober JS, Bothwell AL (1996) Porcine endothelial CD86 is a major costimulator of xenogeneic human $\mathrm{T}$ cells: cloning, sequencing, and functional expression in human endothelial cells. J Immunol 157: 3838-3844.

Malemud CJ (2015) Biologic basis of osteoarthritis: state of the evidence. Curr Opin Rheumatol 27: 289-294.

McGregor CG, Ricci D, Miyagi N, Stalboerger PG, Du Z, Oehler EA, Tazelaar HD, Byrne GW (2012) Human CD55 expression blocks hyperacute rejection and restricts complement activation in Gal knockout cardiac xenografts. Transplantation 93: 686-692.

Mitchelson AJ, Wilson CJ, Mihalko WM, Grupp TM, Manning BT, Dennis DA, Goodman SB, Tzeng TH, Vasdev S, Saleh KJ (2015) Biomaterial hypersensitivity: is it real? Supportive evidence and approach considerations for metal allergic patients following total knee arthroplasty. Biomed Res Int 2015: 137287.

Murray AG, Khodadoust MM, Pober, JS, Bothwell AL (1994) Porcine aortic endothelial cells activate human T cells: direct presentation of MHC antigens and costimulation by ligands for human CD2 and CD28. Immunity 1: 57-63.

Musumeci G, Aiello FC, Szychlinska MA, Di Rosa M, Castrogiovanni P, Mobasheri A (2015) Osteoarthritis in the XXIst century: risk factors and behaviours that influence disease onset and progression. Int J Mol Sci 16: 6093-6112.

Niemann H, Petersen B (2016) The production of multi-transgenic pigs: update and perspectives for xenotransplantation. Transgenic Res 25: 361-367.

Niemietz T, Zass G, Hagmann S, Diederichs S, Gotterbarm T, Richter W (2014) Xenogeneic transplantation of articular chondrocytes into full-thickness articular cartilage defects in minipigs: fate of cells and the role of macrophages. Cell Tissue Res 358: 749-761. 
Oehme D, Goldschlager T, Ghosh P, Rosenfeld JV, Jenkin G (2015) Cell-based therapies used to treat lumbar degenerative disc disease: a systematic review of animal studies and human clinical trials. Stem Cells Int 2015: 946031.

Oussedik S, Tsitskaris K, Parker D (2015) Treatment of articular cartilage lesions of the knee by microfracture or autologous chondrocyte implantation: a systematic review. Arthroscopy 31: 732-744.

Pers YM, Ruiz M, Noël D, Jorgensen C (2015) Mesenchymal stem cells for the management of inflammation in osteoarthritis: state of the art and perspectives. Osteoarthritis Cartilage 23: 2027-2035.

Pulai JI, Chen H, Im H, Kumar S, Hanning C, Hegde PS, Loeser RF (2005) NF-kappa B mediates the stimulation of cytokine and chemokine expression by human articular chondrocytes in response to fibronectin fragments. J Immunol 174: 5781-5788.

Resch T, Fabritius C, Ebner S, Ritschl P, Kotsch K (2015) The role of natural killer cells in humoral rejection. Transplantation 99: 1335-1340.

Rollins SA, Kennedy SP, Chodera AJ, Elliott EA, Zavoico GB, Matis LA (1994) Evidence that activation of human $\mathrm{T}$ cells by porcine endothelium involves direct recognition of porcine SLA and costimulation by porcine ligands for LFA-1 and CD2. Transplantation 57: 17091716.

Romaniuk A, Malejczyk J, Kubicka U, Hyc A, Olszewski WL, Moskalewski S (1995) Rejection of cartilage formed by transplanted allogeneic chondrocytes: evaluation with monoclonal antibodies. Transpl Immunol 3: 251-257.

Rushworth SA, Bravery CA, Thompson S (2001) Human CD154 induces activation of porcine endothelial cells and up-regulation of MHC class II expression. Transplantation 72: 127-132.

Sacks SH, Zhou W (2012) The role of complement in the early immune response to transplantation. Nat Rev Immunol 12: 431-442.

Saris D, Price A, Widuchowski W, Bertrand-Marchand M, Caron J, Drogset JO, Emans P, Podskubka A, Tsuchida A, Kili S, Levine D, Brittberg M; SUMMIT study group (2014) Matrix-applied characterized autologous cultured chondrocytes versus microfracture: two-year follow-up of a prospective randomized trial. Am J Sports Med 42: 1384-1394.

Schett G, Dayer JM, Manger B (2016) Interleukin-1 function and role in rheumatic disease. Nat Rev Rheumatol 12: 14-24.

Schneider MK, Seebach JD (2008) Current cellular innate immune hurdles in pig-to-primate xenotransplantation. Curr Opin Organ Transplant 13: 171177.

Slone RM, MacMillan M, Montgomery WJ (1993) Spinal fixation. Part 1. Principles, basic hardware, and fixation techniques for the cervical spine. Radiographics 13: 341-356.

Smith B, Sigal IR, Grande DA (2015) Immunology and cartilage regeneration. Immunol Res 63: 181-186.
Sommaggio R, Máñez R, Costa C (2009) TNF, pig CD86 and VCAM-1 identified as potential targets for intervention in xenotransplantation of pig chondrocytes. Cell Transplant 18: 1381-1393.

Sommaggio R, Cohnen A, Watzl C, Costa C (2012) Multiple receptors trigger human NK cell-mediated cytotoxicity against porcine chondrocytes. J Immunol 188: 2075-2083.

Sommaggio R, Pérez-Cruz M, Brokaw JL, Máñez R, Costa C (2013) Inhibition of complement component C5 protects porcine chondrocytes from xenogeneic rejection. Osteoarthritis Cartilage 21: 1958-1967.

Sommaggio R, Bello-Gil D, Pérez-Cruz M, Brokaw JL, Máñez R, Costa C (2015) Genetic engineering strategies to prevent the effects of antibody and complement on xenogeneic chondrocytes. Eur Cell Mater 30: 258-270.

Stone KR, Walgenbach AW, Abrams JT, Nelson J, Gillett N, Galili U (1997) Porcine and bovine cartilage transplants in cynomolgus monkey. I. A model for chronic xenograft rejection. Transplantation 63: 640-645.

Stone KR, Ayala G, Goldstein J, Hurst R, Walgenbach A, Galili U (1998) Porcine cartilage transplants in the cynomolgus monkey. III. Transplantation of alphagalactosidase-treated porcine cartilage. Transplantation 65: $1577-1583$.

Stone KR, Pelsis JR, Surrette ST, Walgenbach AW, Turek TJ (2015) Meniscus transplantation in an active population with moderate to severe cartilage damage. Knee Surg Sports Traumatol Arthrosc 23: 251-257.

Sullivan JA, Oettinger HF, Sachs DH, Edge AS (1997) Analysis of polymorphism in porcine MHC class I genes: alterations in signals recognized by human cytotoxic lymphocytes. J. Immunol 159: 2318-2326.

Tadaki DK, Craighead N, Saini A, Celniker A, Burkly LC, Lee KP, Chute JP; Harlan DM, Kirk AD (2000) Costimulatory molecules are active in the human xenoreactive T-cell response but not in natural killermediated cytotoxicity. Transplantation 70: 162-167.

Vadori M, Cozzi E (2015) The immunological barriers to xenotransplantation. Tissue Antigens 86: 239-253.

Vivier E, Tomasello E, Baratin M, Walzer T, Ugolini S (2008) Functions of natural killer cells. Nat Immunology 9: 503-510.

Vonk LA, de Windt TS, Slaper-Cortenbach IC, Saris DB (2015) Autologous, allogeneic, induced pluripotent stem cell or a combination stem cell therapy? Where are we headed in cartilage repair and why: a concise review. Stem Cell Res Ther 6: 94.

Wang H, Yang YG (2012) Innate cellular immunity and xenotransplantation. Curr Opin Organ Transplant 17: 162-167.

Yanaga H, Imai K, Fujimoto T, Yanaga K (2009) Generating ears from cultured autologous auricular chondrocytes by using two-stage implantation in treatment of microtia. Plast Reconstr Surg 124: 817-825.

Yang L, Güell M, Niu D, George H, Lesha E, Grishin D, Aach J, Shrock E, Xu W, Poci J, Cortazio R, Wilkinson RA, Fishman JA, Church G (2015) Genome-wide inactivation of porcine endogenous retroviruses (PERVs). Science 350: 1101-1104. 


\section{Discussion with Reviewers}

Reviewer I: Can the authors comment on how the xenogeneic rejection process may differ in instances of pathology, such as RA or OA, where an inflammatory environment is already present? Given that such joint pathologies requiring cartilage replacement are associated with an existing dysregulated inflammatory environment, with complement proteins and antibodies already known to play an active role. Can the authors advise on which proposed strategies would be most beneficial in these instances, or whether the xenogeneic rejection process would differ compared to a relatively healthy joint?

Authors: The environment of the defect can certainly have an impact, as the presence of pro-inflammatory cytokines will activate the PCs and exacerbate rejection. It makes sense that a cell therapy approach is conducted under conditions in which inflammation is minimized (i.e. by using anti-inflammatory agents). Interestingly, PCs may show small advantages such as not responding to human IFN $\gamma$ (due to receptor incompatibility). Nevertheless, the current concept of xenotransplantation is being able to incorporate genetic engineering approaches that target multiple hurdles including key pro-inflammatory cytokines such as TNF. Regarding the presence of reactive antibodies and complement associated to disease, we can speculate that the genetic engineering strategies directed to control the effect of xenogeneic complement activation should help regardless of the origin of the antibodies. In particular, we described in Sommaggio et al. (2015) that high expression of human complement regulatory proteins DAF and CD59 was quite effective in controlling complement activation. However, studies directed to determine what genetic modifications are the most protective to PCs from both processes would be certainly of value.

Reviewer II: What is the contribution of phagocytosisbased indirect activation of $\mathrm{CD} 4+\mathrm{T}$ cell-mediated xenograft rejection?

Authors: We expect the indirect pathway of $\mathrm{T}$ cell activation to be initially a major contributor to xenograft rejection. We already know from a mouse model that CD4+ $\mathrm{T}$ cells are critical for pig cartilage rejection (Costa et al., 2003) and that PCs do not express SLA-II to be able to activate directly CD4+ T cells (Sommaggio et al., 2009). However, approaches directed to prevent human monocyte /macrophage activation such as expression of CD47 and/ or CD200 on the PC could help reduce phagocytosis and subsequent antigen presentation to CD4+ T cells.

Reviewer II: Many human immunity-based challenges exist in the attempt to overcome at least major rejection mechanisms on the way toward the meaningful solution/s for the successful xenograft transplantation. These include multiple levels of genetic modifications steps in targeted tissues or whole organism of model species (primarily pigs). How do the authors see these challenges when compared with those present in autologous/allogenic chondrocyte/MSC-based approaches?

Authors: We are convinced that young piglets could be a source of very high quality chondrocytes with high chondrogenic activity. The right passage that preserves this capacity remains to be established, but initially it may be even possible to use directly isolated cells without further culture/expansion. We have extensive experience in using chondrocytes cryopreserved at passage 0 and believe this could be a form that could be transferred to the clinical setting. This situation is very different to that of autologous chondrocyte implantation which uses a limited number of cells that can be isolated and expanded from a biopsy of human cartilage or even allogeneic tissue for subsequent expansion with the associated loss of chondrogenic capacity. The allogeneic tissue has the additional drawback of the low availability and the quality loss during tissue preservation. Thus, it seems that the limitations for these techniques can be managed, but not solved. The potential for MSCs appears higher as these are relatively more available, although their capacity to form good quality hyaline cartilage remains a challenge. The challenge for xenotransplantation is different as the real limit has not been established yet. For now, a major effort is needed to select and test each of the various genetic modifications required to attain successful engraftment. We are now working on establishing a simple small animal model that could help in this task.

Reviewer II: Even if successful steps will be made, what is/are the comparative advantage/s (biomechanical and functional) of cartilage-like tissue formed from porcine chondrocytes in comparison to the one formed from human-based grafts?

Authors: Some work has already been done in this regard with in vitro-generated cartilage, but more testing would be required in preparation for the clinical setting. Thus, the advantages remain to be established. Nevertheless, expectations are high considering that expansion of the chondrocytes may be minimized or even avoided if found beneficial for the outcome.

Reviewer II: Is there any evidence of any biomaterial commonly used as support (carrier/scaffold) for human grafts in xenograft settings?

Authors: It is my understanding that the materials being developed and applied for MACI in the clinical setting would be the first choice for testing in a xenogeneicbased therapy. Nevertheless, I am aware that progress is being made for selecting more advanced biomaterials that promote the chondrogenic potential of MSCs. One or more of these materials may prove to be advantageous for the development of a xenogeneic chondrocyte-based product.

Reviewer III: The strategies to prevent rejection of xenogeneic chondrocytes are interesting and based on solid data. However, a single modification is unlikely to solve the problem of ultimate rejection of xeno grafts. Can the authors comment on the following points:

1. The capacity/strategy for ensuring success of genetic modification of porcine chondrocytes

2. Potential strategies to enable modification of multiple genes

3. Length/timing of expression required

4. Clinical impediments to such strategies 
5. Would the strategy imply the use of genetically modified porcine chondrocytes implanted as an engineered construct or is there a possibility of altering chondrocytes in situ and using porcine cartilage as a repair strategy?

Authors: 1. We propose to initiate this process by selecting the appropriate genetic engineering modifications that target the cell surface carbohydrate remodeling in combination with a complement inhibitor (i.e. H-transferase and human CD59). Many pigs are already available for this type of approach. Subsequent rounds of genetic modifications could be intended to control the cellular responses for $\mathrm{T}$ cells, NK cells and monocytes/macrophages. Control of pro-inflammatory cytokines or use of pro-survival genes may be a required target as well. Testing of efficacy could be conducted simultaneously for groups of molecules with distinct but related goals. We are setting up a simple rat model that could be helpful for this purpose. Preclinical studies in non-human primates should be organized when a multi-transgenic approach has already shown benefit/ success in a small animal model.

2. With current genome-editing technologies such as TALENs and CRISPR/Cas9, it is possible to conduct multiple rounds of genetic modifications at the cellular level prior to transfer of embryos to produce pigs. This is well described by Niemann and Petersen (2016). Furthermore, there is also the $2 \mathrm{~A}$ system that allows linking proteins produced simultaneously within the same construct (single promoter) (Fisicaro et al., 2011).

3. A constitutive expression of the transgenes is advisable in most cases, although this could be combined with an additional construct that drives regulated expression when considered appropriate. This regulation may be of interest in the case of diseased joints in which the release of cytokines may lead to higher requirements for protection. Regarding the need of gene disruptions, the knockouts should preferentially target the whole animal. Nevertheless, there is the possibility of selective targeting to cartilage with a Cre-loxP inducible system or equivalent if they produce a deleterious effect.

4. It is my understanding that the most relevant impediment will be rejection. The work has to be done to reach the point which allows determining whether long-term engraftment can be achieved.

5. I envision that xenotransplantation can potentially offer the advantage of using an off-the-shelf product based on genetically modified chondrocytes in combination with an advanced biomaterial/scaffold. It should follow the steps of MACI, but without the need of obtaining cartilage from the patient and the subsequent culture/expansion of the cells. However, I cannot exclude the possibility that gene therapy strategies could be considered for combination in certain cases, such as in OA and RA patients, with more complex disease settings.

\section{Additional Reference}

Fisicaro N, Londrigan SL, Brady JL, Salvaris E, Nottle MB, O'Connell PJ, Robson SC, d'Apice AJ, Lew AM, Cowan PJ (2011) Versatile co-expression of graft-protective proteins using 2A-linked cassettes. Xenotransplantation 18: 121-130.

Editor's Note: Scientific Editor in charge of the paper: Martin Stoddart. 